This is the author's final, peer-reviewed manuscript as accepted for publication. The publisher-formatted version may be available through the publisher's web site or your institution's library.

\title{
The importance of therapist/client ethnic/racial matching in couples treatment for domestic violence
}

Horst, K., Mendez, M., Culver-Turner, R., Amanor-Boadu, Y., Minner, B., Cook, J., Stith, S. M., \& McCollum, E.

\section{How to cite this manuscript}

If you make reference to this version of the manuscript, use the following information:

Horst, K., Mendez, M., Culver-Turner, R., Amanor-Boadu, Y., Minner, B., Cook, J., ... McCollum, E. (2012). The importance of therapist/client ethnic/racial matching in couples treatment for domestic violence. Retrieved from http://krex.ksu.edu

\section{Published Version Information}

Citation: Horst, K., Mendez, M., Culver-Turner, R., Amanor-Boadu, Y., Minner, B., Cook, J., ... McCollum, E. (2012). The importance of therapist/client ethnic/racial matching in couples treatment for domestic violence. Contemporary Family Therapy, 34(1), 57-71.

Copyright: (C) Springer Science+Business Media, LLC 2012

Digital Object Identifier (DOI): doi:10.1007/s10591-012-9174-X

Publisher's Link: http://www.springerlink.com/content/y1m04331701v8284/

This item was retrieved from the K-State Research Exchange (K-REx), the institutional repository of Kansas State University. K-REx is available at http://krex.ksu.edu 
Running head: ETHNIC/RACIAL MATCHING

\title{
The Importance of Therapist/Client Ethnic/Racial Matching in Couples Treatment for Domestic Violence
}

\begin{abstract}
Outcome research indicates a relative degree of variability regarding the effectiveness of client and therapist ethnic/racial matching (see Cabral and Smith 2011, Shin et al. 2005). Considering these findings, our study hopes to further understand the complexity behind ethnic/racial matching in treatment. In this study, we examined interviews with clients and therapists regarding ethnic/racial matching in couples treatment for domestic violence (e.g., McCollum and Stith 2008). Our findings indicated that ethnic/racial matching is a complex multi-faceted issue and connected ethnic/racial matching with issues of culture, human experience, and others. We recommend clinicians consider the complexity of ethnic/racial matching in practice.
\end{abstract}

Horst, K., Mendez, M., Culver Turner, R., Amanor Boadu, Y. Minner, B., Cook, J., Stith, S.M., \& McCollum, E. (2012). Ethnic or racial matching in couples treatment for domestic violence. Contemporary Family Therapy, 34, 1, 57-71. 


\section{The Importance of Therapist/Client Ethnic/Racial Matching in Couples Treatment for}

\section{Domestic Violence}

Between 2010 and 2050, it is estimated that the U.S. population will become more ethnically and racially diverse, with the cumulative ethnic and racial minority population (Asians, Blacks and Latino/Latinas) projected to become the majority by 2042 (Vincent and Velkoff 2010). Additionally, more recent studies have found that ethnically diverse Americans underutilize mental health services (U.S. Surgeon General, 2001). Considering the changing national demographics as well as the disparity of mental health utilization, mental health practitioners, including those delivering treatment for domestic violence, face an obligation to ensure that the specific needs of diverse clients are being met.

One specific point of interest with regards to this problem is the ethnic/racial matching of therapist and client. Research regarding ethnic/racial matching has recently received considerable attention; however the literature is primarily concerned with the impact on client outcomes (see Cabral and Smith 2011, Shin et al. 2005). Findings regarding the impact of ethnic/racial matching have been inconclusive which highlights the inherent complexity of this issue. Studies that are primarily focused on client outcomes may be too limited to fully investigate the process and experience of ethnic/racial matching. Furthermore, we suspect that the context in which clients are receiving treatment may account for some of the variability of findings in other studies. In our study we sought to further understand this complex issue by 


\section{ETHNIC/RACIAL MATCHING}

examining the perceptions of both ethnic minority clients involved in a couples' treatment program for domestic violence and the therapists who worked with them with regards to the impact of therapist/client ethnic/racial matching. We wanted to go beyond looking at statistically significant changes in outcome variables which might be related to ethnic/racial matching to learning from clients and therapists about their perceptions of the importance of therapist/client ethnic/racial matching. By using a qualitative methodology, we anticipated that our analysis would allow for more in-depth understanding of this experience.

\section{LITERATURE REVIEW}

\section{Ethnic/Racial Matching in Therapy}

As mentioned above, findings regarding the impact of client and therapist ethnic/racial matching have garnered mixed results. Several quantitative studies have focused on the impact of ethnic/racial matching on specific treatment outcomes (e.g., Sue et al. 1991). For example, a study $(n=13,439)$ that utilized the Global Assessment Scale (GAS) found that ethnic matching did not significantly influence treatment outcome for clients who were English speaking, although ethnic/linguistic matching did improve outcomes for clients who were non-English speaking (Sue et al. 1991). These results were supported by a study that focused on 116 African American cocaine-dependent participants within an outpatient treatment facility (Sterling et al. 2001), which found no meaningful effects on retention rate or outcome based on ethnic/racial matching. A meta-analytic review of 10 studies focused on ethnic/racial matching and retention, treatment tenure, and post-treatment function status revealed varying results (Shin et al. 2005). However, when the researchers utilized the conservative effects model on the studies, they found no overall effects of ethnic/racial matching for African American or European American clients. Studies, however, examining ethnic/racial matching between therapist and adolescent and young 


\section{ETHNIC/RACIAL MATCHING}

adult clients (Flicker et al. 2008; Wintersteen et al. 2005) have suggested that ethnic/racial matching does impact treatment outcomes. Ethnically matched Hispanic adolescents reported significantly lower substance use after treatment than did Hispanic adolescents who were not ethnically matched. However, Anglo adolescents' substance use was not related to the ethnicity of the therapist (Flicker et al., 2008).

The issue of client and therapist ethnic/racial matching might have an impact beyond specific treatment outcomes. It is much more feasible to assume that ethnic/racial matching might impact elements of treatment such as the therapeutic alliance, and thus have an indirect effect on treatment success. A handful of studies have investigated the impact of ethnic/racial matching on other outcome variables related to treatment (e.g. treatment satisfaction, therapeutic alliance, etc.) One study compared client-therapist dyads of the same race $(n=657)$ and dyads of different races $(n=184)$ measuring client satisfaction and evaluation of treatment by the client and therapist, and found no significant differences on the Client Satisfaction Questionnaire and the Client's Evaluation of Treatment between the racially matched and non-matched dyads. However, significant differences were indicated on the Therapist's Evaluation of Treatment on four of the questions, suggesting some difference in the therapist's perception of treatment (Murphy et al. 2004). Overall, therapists had less positive perceptions about the effectiveness of treatment when they were working with racially different clients than when they were working with racially matched clients.

Other studies have suggested that ethnic/racial matching does impact therapeutic factors like termination rates and perceived therapist credibility. A national evaluation of the PTSD Clinical Teams program of the Department of Veterans Affair $(n=4,726)$ found significant differences in retention and termination rates based on racial matching. Significantly more of the 


\section{ETHNIC/RACIAL MATCHING}

European American clinicians/African American clients and African American clinicians/ European American clients terminated within 3 months than did the racially matched clients (Rosenheck et al. 1995). Farismadan et al. (2007) utilized the Brief Symptom Inventory, Working Alliance Inventory and Counselor Effectiveness Rating scale to measure therapeutic outcomes, bond with the therapist, and therapist credibility with a sample of 100 ethnic minority clients evenly split between matched and non-matched therapeutic dyads. The matched participants scored significantly higher in therapeutic outcome, bond with the therapist, and perception of therapist credibility. Thus, while some studies indicate that ethnic/racial matching of therapists and clients does not impact outcome, retention or termination rates, other studies indicate that ethnic/racial matching does have a positive influence.

The diversity of findings mentioned above indicates that the impact of therapist and client ethnic/racial matching is complex. This complexity may require research which lends itself to a methodology which is more open to the complexity and nuance behind this issue. Qualitative methods of inquiry will help to investigate this issue with “depth, openness, and detail”, unfortunately, there have been few qualitative studies examining ethnic/racial matching (Patton 2002, pp. 14). Two recent qualitative studies have examined clients’ perceptions of therapy experiences and have addressed the question of therapist race or ethnicity. Chang and Berk (2009) examined 16 ethnic/racial minority clients who received therapy from 16 European American therapists. Half of the clients were unsatisfied with therapy $(n=8)$ and reported that their therapists lacked group-specific knowledge and culture-specific knowledge. For example, clients reported that their therapists' lacked knowledge pertaining to sexual minorities, racism, discrimination, and stigma related to psychological problems. Three quarters of these clients ( $n$ = 6) described experiences in which the therapist lacked awareness of power and privilege; on 


\section{ETHNIC/RACIAL MATCHING}

the other hand, the clients satisfied with therapy $(n=8)$ did not describe any experiences in which they perceived a lack of awareness. The satisfied clients described their therapist as a

professional, an expert, and one who demonstrated general therapeutic competence and skills. In an additional qualitative study, the researchers interviewed mental health providers utilizing Consensual Qualitative Research (CQR) with a sample of five African American and seven European American licensed psychologists (Knox et al. 2003). CQR is a collaborative approach in which research team members collectively reach a consensus about the meaning of the data (Hill, 2012). Using this approach, Knox and colleagues found that African American psychologists consistently addressed race when it was part of the client's presenting issue while European American psychologists reported addressing it only if clients discussed it. Both reported that discussions regarding race had positive effects.

The literature from the general psychotherapy arena exemplifies the complexity regarding the value of ethnic/racial matching between therapists and clients. Some studies have found that it improved outcome, especially with adolescents, while other studies find that matching did not impact elements of treatment.

\section{Ethnic/Racial Matching in Domestic Violence Treatment Programs}

Research regarding ethnic/racial matching among client and therapist within the context of domestic violence treatment has received considerably less attention. Contextual elements of treatment are an important consideration when investigating the issue of ethnic/racial matching. For example, the impact of ethnic/racial matching on treatment conducted in an inpatient psychiatric hospital might not mirror the impact in couples treatment for domestic violence. Especially in light of the above mentioned findings, the complexities behind the issue of ethnic/racial matching calls for a thorough investigation of this issue within a variety of contexts. 


\section{ETHNIC/RACIAL MATCHING}

The particular focus of this study is the influence of ethnic/racial matching within the context of couples treatment for domestic violence. Previous studies which examined racial diversity in domestic violence treatment have focused on batterer intervention treatments. Taft, Murphy, Elliot, and Keaser (2001) found, in their study of 101 batterers, that the strongest predictor of batterer program incompletion was race, with African Americans being least likely to complete the counseling program. One explanation offered by the authors for the high dropout rate and recidivism was the use of a "color-blind” philosophy focusing mainly on abusive behaviors and the nature and impact of abuse, rather than focusing on any culturallysensitive areas, which may have been considered by the therapists as tangential. Gondolf and Williams (2001) suggest that culturally focused domestic violence counseling, which they perceived as going beyond cultural sensitivity and placing violence in a cultural context and explicitly integrating cultural issues into the program, with groups composed of racially homogenous batterers with a racially matched therapist might improve treatment outcome for minority clients. Gondolf and Williams suggest that in an African American culturally focused batterer program, some topics of discussion may include perceptions of the police, relationships with women, manhood in the African American community, and reactions to discrimination and prejudice. However, outcome research on such programs is limited. Gondolf (2008) utilized a three-group study to examine the effects of program completion across different batterer programs: culturally-focused counseling in all-African-American groups, conventional counseling in all-African-American groups, and conventional counseling in racially-mixed groups. In all groups, approximately half of the men completed the program, suggesting that accommodating for cultural differences did not have a significant impact on program completion. However, those with high racial identification, measured by Racial Identity 


\section{ETHNIC/RACIAL MATCHING}

Attitudes Scale, were 33\% more likely to complete the African-American programs.

Furthermore, Hancock and Siu (2009), examining immigrant Latino men in culturally sensitive batterer programs, noted that the culturally sensitive approach effectively engaged men in their attempts to stop domestic violence.

The results surrounding culturally sensitive batterer programs indicate a need for further research to examine the influence of ethnic/racial matching in such programs and others targeting the issue of domestic violence. While Gondolf (2008) did not find a statistically significant difference in completion rates based on racial matching, he did find that for some clients matching increased the likelihood that they would complete the program. Through the use of a qualitative methodology, this study will further contribute to a more nuanced understanding of the complexity involved in ethnic/racial matching client and therapist within the context of domestic violence treatment. In this study we sought to listen to the voices of minority clients and their therapists to learn their perspectives about the importance of ethnic/racial matching.

\section{METHODS}

In this study we analyzed interviews conducted with participants in a Domestic Violence Focused Couples Treatment program (Stith et al. 2004) developed with NIMH funding. The treatment was provided by co-therapists working with a single couple or with a multi-couple group for a total of 12 weekly meetings. The treatment model is grounded in solution focused therapy (DeShazer 1988) and utilizes additional psychoeducational components. Each participant was scheduled to be interviewed a total of 4 times -- following the second, fifth, eighth, and final therapy session (i.e., twelfth) to help the program developers adapt the program by learning from clients and therapists about what was helpful and what was not helpful in the 


\section{ETHNIC/RACIAL MATCHING}

program design. The interviews were spaced evenly throughout the treatment program so that the program developers could receive feedback from clients throughout the program, rather than simply at the end of the program. One goal of the original project was to learn from the clients how to make the treatment more useful for minority clients. Interviews with minority clients and their partners and therapists were analyzed for this project.

The treatment program, Domestic Violence Focused Couples Treatment, is based on the Solution-Focused Brief Therapy (SFBT) work of de Shazer and Berg (de Shazer, et al., 2007). The basic tenets of SFBT guided the treatment provided, the decision to interview clients throughout the treatment process to learn from them about how to improve the manualized treatment program, and the decision to use thematic analysis to analyze the data. Foundational to SFBT is the "appreciative stance." This is a basic belief that clients bring not only problems but also large measures of competence, resources, and strength when they come to treatment. One way of demonstrating an appreciation for what clients bring to therapy is to use their feedback to enhance the treatment provided. Another basic tenet of SFBT is that clients' goals for treatment remain in the forefront and structure treatment. The treatment program was developed in collaboration with the perspective of the clients who participated in the program and the therapists who delivered the program. While quantitative data was collected on the outcome of the program (see Stith, Rosen, McCollum, \& Thomsen, 2004; Stith, McCollum, Amanor-Boadu, \& Smith (In press); Stith, McCollum, \& Rosen, 2011), gathering qualitative data to learn from clients and therapists to improve the program makes sense from a SFBT. Also, using thematic analysis, in which themes are drawn from the data inductively, rather than analyzing the data using categories developed from the literature fits with the SFBT approach which guided the treatment. 


\section{ETHNIC/RACIAL MATCHING}

Fifteen heterosexual couple/therapist dyads participating in the treatment program were randomly chosen for a series of interviews designed to understand each participant's experience of the program. In seven of these couples, at least one partner was a member of a minority racial/ethnic group (see Table 1). Interviews with these seven couples (14 individuals) and their therapists comprise the data set for this study. Interviews were completed either directly following the session, or as soon as possible afterward. Clients were interviewed individually because the focus of the treatment was domestic violence and it was important to allow clients to speak freely and to feel safe. Therapists were interviewed together (with their co-therapists), except in a few cases when scheduling problems arose. Two couples dropped out of the treatment program and were interviewed only twice; however, one of these couples did agree to be further interviewed by phone.

A wide range of information was gathered in the interviews on topics including: benefits and challenges of conjoint treatment for intimate partner violence (IPV), effect of having male and female co-therapists, and the value of particular interventions. In this study, we focused on questions regarding how to better improve the treatment for diverse clients. A question in each interview was asked about the importance of matching racially/ethnically diverse clients with similarly diverse therapists, with the preface, "One of our goals is to reach diverse clients and make treatment more relevant for them. How do you think we are doing with that?" Interviewers asked follow up questions to allow participants to express their thoughts more in depth. Followup questions were based on the characteristics of the therapist-client system and the answers to the earlier question. A typical question would be, "I understand that both you and your partner are African American and your co-therapists are White? Is this ever an issue for you? If so, in what way?” To prepare for the follow-up with interviews with clients, the interviews read the 


\section{ETHNIC/RACIAL MATCHING}

previous transcripts and asked appropriate follow-up questions. For example, "the last time you were interviewed you said that you thought the race of the therapist was not as important as the competencies of the therapist. I wonder if you're thinking about this issue has changed over time?” In general, clients did not change their perspective on the issue over time. Questions about the effectiveness of the program for diverse clients were included in the original study in an effort to assess minority clients’ perception about their experience in treatment.

Client participants in this project ranged in age from 19 to 54 with a mean age of 36 years. Every couple was composed of at least one non-white/Caucasian person. Of the client participants, eight were Black/African American, two were Asian (born outside the U.S.), one was Black from South American country, and three were White, with one being born in Europe. Therapist ranged in age from 26 to 34 with a mean age of 30 years of age. Eight of the ten therapists were White, one was White from South America, and one was Black/African American. Four therapists were male and six were female.

\section{Insert Table Here}

Interviewers were graduate students who were trained in qualitative methods by a professor who developed the qualitative aspects of the project. None of the interviewers are researchers in the current project. Data from the interviews were transcribed and made available for secondary data analysis by the current research team.

The current research team (co-authors of this paper) was trained in systems theory to work with couples and families, and two of the researchers developed the manual used in the couples' treatment and were active in the data gathering process. Of the seven authors, five were White; one was Asian American, and one was White from South American. Five of the seven authors completed a 3 credit graduate course in cultural and racial issues in therapy and 


\section{ETHNIC/RACIAL MATCHING}

discussions about our own biases were held during and after data interpretation. Results from our preliminary analyses were discussed with therapists representing other ethnic and racial backgrounds to enhance our confidence in the results.

Transcribed data was analyzed utilizing thematic analysis. Thematic analysis "is a method for identifying, analyzing and reporting patterns (themes) within data” (Braun and Clark 2006). The authors followed the six phases of thematic analysis:1) familiarized themselves with the data, 2) generated initial codes, 3) searched for themes, 4) reviewed themes, 5) defined and named themes, and 6) produced the report (Braun and Clark 2006). Initially, one author read all the transcripts to select couples in which at least one member was of a ethnic/racial minority since those were asked about ethnic/racial matching in therapy. A second author reviewed all the transcripts to make sure that all information from each transcript that in any way dealt with race or ethnicity was included in the sample from the transcripts that was analyzed for this project.. Six of the co-authors familiarized themselves with the data by reading each of the selected transcripts for the 7 couples (14 different individuals). Next these co-authors generated initial codes from all the transcripts. These six co-authors met weekly to review initial codes and to determine relevant themes making sure that all themes that were considered significant for the purpose of this study captured data that were relevant to the research questions (Braun and Clark 2006). In a panel with six of the co-authors present, an open discussion took place in order to select the appropriate label for themes. Individually, six of the co-authors reviewed all transcripts to categorize quotes within each of the themes previously agreed upon. In a final meeting, the first six co-authors conducted a review of the data and themes. Also, findings were discussed by all authors and analyzed for internal homogeneity addressing the question: Do quotes selected to illustrate a theme capture one concept? Finally, themes also were checked for external 


\section{ETHNIC/RACIAL MATCHING}

heterogeneity making sure that each theme is distinct from the others. After themes and quotes were selected, six of the co-authors took a theme and wrote the section referring to that theme. The first author reviewed each written section and edited to insure that the final report was written clearly. Finally, the final co-author read and revised the manuscript based on his perspective as a developer of the treatment model.

\section{FINDINGS}

Analysis of participant interview transcripts revealed the complexity of the issues surrounding racial/ethnic matching within the context of couples' treatment for domestic violence, as evidenced by the identification of themes related to: culture is more relevant than race, violence is a "human problem" and not a ethnic/racial problem, therapist qualities are more important than therapist race, ethnic/racial matching can create a 'shared understanding,' therapist interventions or awareness of culture can be important, and ambivalence.

\section{Culture is More Relevant than Race}

One theme we identified in conversations with clients and therapists about ethnic/racial matching was that some participants believed that considerations of culture were more relevant to treatment than considerations of race. This particular theme was often expressed in terms of cultural differences between marital partners or cultural differences between clients and therapists impacting treatment effectiveness more than matching or lack of a matching in race between clients and therapists. For instance, when asked about the relevance of racial matching, therapists often replied by identifying broader cultural concerns pertinent to therapy. One white American male therapist working with a Black Hispanic and African American couple stated, "I think there is more in the difference in culture between him and us and him and his wife than 


\section{ETHNIC/RACIAL MATCHING}

there was race difference." Cultural issues identified by therapists included religious differences between partners, politics or political differences, cultural beliefs regarding gender roles, or language differences between partners or between therapists and clients. At a later point in the interview, the same therapist said,

I do believe that there may be some cultural issues.. um.., especially, well actually for both, the male partner has some really strong religious beliefs which I think affect the way he interacts, he holds very tightly to the idea that the man is the head of the household, so if you consider religion kind of a cultural thing, I think that would be an aspect of the relationship that could be important, but it is not something that we have explored directly...And the woman, I think, she is from the United States, so I think there might be some cultural pieces there as far as family and gender roles and expectations about relationships..

Several clients expressed similar ideas, i.e., that attending to cultural issues or differences was more relevant to their treatment than was racial matching. For instance, one white American male client with an Asian partner working with two white American therapists stated, "When you talk about race, it's one thing. When you talk about culture, it's a different thing. So, in terms of race, I didn't see any difference at all. Culture wise yes, there probably might be a difference." Additionally, a Black client from South America challenged the idea of racial matching by highlighting assumptions about similarities or differences based on clients' race, which often neglect the amount of cultural variability that might exist within races. With regard to the lack of racial matching between himself and his therapists, he stated, 


\section{ETHNIC/RACIAL MATCHING}

No, it doesn't bother me at all. I don't feel as though there is any misunderstanding between us. I didn't grow up around a lot of racial tension, so I sometimes feel as though I can be understood by white people better than a lot of African Americans.

\section{Domestic Violence as a Human Problem}

Analyses of the interviews also suggested that many clients participating in a couples treatment program for IPV perceived issues of violence as one that transcended race. In response to being asked about the relevance of ethnic/racial matching, clients often responded by stating that although clients may come from diverse cultural backgrounds, the issue of violence is universal. In response to being asked about whether issues of race or ethnicity impacted treatment, one African American female client stated, "Different people deal with the same situations.” Many clients also noted that treating clients experiencing domestic violence may not require addressing issues of race or ethnicity. One black Caribbean female client stated: It [race or ethnicity] has nothing to do with it because these problems, is like everybody's. It's just that everybody has problems. It doesn't' matter whether you're green, blue, purple, or whatever. You know, because the same problems you can have with the Black or the White and the same problems happen in the home and communication skills is a skill that people need. If we don't have that, then we need somebody to help us to bring that out. So it doesn't' really matter where you're from.

Clients emphasized that what perpetuates domestic violence goes beyond race or ethnicity. A Black, female client when asked if she thought that the program would be more helpful if therapists were of the same race as the clients, said:

No, Because I feel that we're all the same deep down. We all have feelings...if they're [therapists] human, we all cry....And maybe they [therapists] can understand my feelings. 


\section{ETHNIC/RACIAL MATCHING}

That's all. Race doesn't matter to me. Everybody. White, Black. We all have problems. No one is perfect.

However, clients often made statements of this nature as a disclaimer before mentioning any issues of race that might have arisen in treatment, as evidenced by one black female participant's words: "I think we're all people, we all deal with the same situations. Maybe someone black might deal with a different situation than a person who is white because of the way they was brought up.” On one hand, this client states, “we all deal with the same situations,” but on the other hand, she also notes that people of different races might "deal with a different situation.” This quote also highlights ambivalence toward issues of race and ethnicity, which we will explore further in a subsequent section.

\section{Therapist Qualities}

Another theme highlighted by participants was the emphasis on "therapist qualities” over therapist ethnicity/race. When client participants were asked if they thought working with a therapist of the same race was important to their overall treatment, many answered by stating that race or ethnicity wasn't as important to them as other qualities of their therapists. One African American male participant said, "you would want the person [therapist] to be a person first, not the color of their skin, it's more about who they are."

Participants noted qualities such as, self-esteem, perceptive abilities, compassion, being supportive, and having good listening skills as more important for their therapist to possess than a similar ethnicity/race. Another quality mentioned by participants was therapist competency. One client said, "If you know your field and you know what you're doing then that's fine. I don't care who you are. Because they know what they're doing and they know their job.” One African American male participant noted that the therapist's ability to create a safe and open environment 


\section{ETHNIC/RACIAL MATCHING}

is what facilitated his success, "[I] felt like you [referring to clients in the program] were being helped...like you weren't wasting my time 'so let's just get this over with'...I never felt that...never were they condemning or discriminative in any way....” Another African American female participant specifically outlined how listening was more important in therapy than ethnicity/race:

It does not matter to me as far as race, because if you're not from the same exact background that I'm from, then you won't understand to the fullest. But, if you're there listening and trying to understand, than it's helpful.

Participants who described therapist qualities as more important than ethnicity/race were from a diversity of backgrounds. For example, one African American participant commented that race would not have influenced the appreciated qualities of the therapist, ...they could have been two African American counselors with us and they could have been not helpful at all. They could have been not even listening, not even trying to listen. I don't even know their races, but they weren't black. But, I felt they were trying to listen to me, but that was helpful. The race didn't matter.

Just as with the first two themes described above, when prompted about the relevance of ethnicity/race in treatment, clients often diverted their answers away from issues of race to what they felt was more applicable, in this case therapist qualities.

\section{Matching Leads to Shared Understanding}

Although participants often indicated that the qualities of the therapists were more important than racial matching, several participants alluded to the possibility that clients and therapists of the same ethnic/racial background could share similar experiences. These similar experiences mentioned by the participants consisted of shared cultural norms, childhood 


\section{ETHNIC/RACIAL MATCHING}

experiences, familiar cultural language, and relatable struggles with ethnic/racial inequality and discrimination.

Although the shared experiences varied by participant, several mentioned that ethnic/racial similarities with the therapist could contribute to a better understanding of the client. One Black participant stated, you see someone that looks like - looks like you, could relate a little bit more um not that I can't relate to you as a woman but um, you know, it's just that common-commonness that helps you kind of like look, you know, this is what's going on with me, and you know, and be able to really relate in that-that way....

A few clients indicated that racial/ethnic matching of client and therapist could result in the client feeling more comfortable with treatment. This increased level of comfort could than result in the client disclosing more personal information, and thus leading the client to feel more understood. One Black female client who had a Black female therapist and a White male cotherapist commented,

"Yes, \{therapist name adds flavor to the therapy. She enhances the sessions by sharing the same background, culture. Not to say that one is better than the other, they are both great. \{Therapist name\} and I share the same culture, it's like coming home. It's comfortable. It's like sharing the same language.”

Both client and therapist participants mentioned that sharing culture may contribute positively to treatment, as evidenced by the above statement, "She enhances the sessions by sharing the same background, culture." However, participants also stated that there seemed to be an assumption that those of the same ethnicity/race shared something in regards to culture. One African American female therapist participant stated, "I think they assume that we(her and 


\section{ETHNIC/RACIAL MATCHING}

her client) share the same culture, they assume we share things.” One white therapist who thought that the lack of ethnic/racial matching between her and her clients was not interfering with treatment noted that ethnic/racial matching could possibly allow for a more personal understanding of the client’s problem, especially when related to specific interventions, ...when we do the genogram, that might be a time when there will be a familiarity or sharing of cultures when we're talking about families and generations and what people are accustomed to, a minority therapist might have a better understanding of how minority families operate....

\section{Ambivalence}

Another theme that we inferred from the clients' data was a sense of ambivalence when they were asked about race and culture. In response to a question about whether it would be better to have a therapist and group members of the same race, one African American female client who participated in a multi-couple group said, "that is tricky, because although you do want someone you can relate of your race, you do want the insight of other races to see what their lifestyle habits, to kind of like observe something different”. A different client and her partner also talked about the benefits of identifying with your therapist because he or she shares the same race and culture; however, they also discussed the benefit of having someone with a different perspective who can help them see things in a different light. We identified this theme of ambivalence not just in the words that participants used to respond to questions about racial matching, but in the tone and the process of their conversations. As noted above, participants often went back and forth between ideas of how or why ethnic/racial matching might be a good idea, such as in leading to a shared understanding, to how or why it might not be as important as something else, such as cultural competency, or therapists’ qualities. 


\section{ETHNIC/RACIAL MATCHING}

\section{Therapist Perceptions}

In addition to asking clients about their views of ethnic/racial matching, data also were collected regarding therapists’ views on the relevance of racial/ethnic matching in couples’ treatment for domestic violence. Less variety in responses was given by the therapists compared to clients. Four of the six therapists interviewed reported explicitly mentioning ethnic/racial differences between themselves and their client at some point in treatment. One White male therapist reported stating to his client, "I can't pretend to know what it's like to be a Black woman, so if I'm not getting it, I'm going to depend on you to let me know.” A white female therapist also stated "I don't think those walls are down for me and every time I bring up that [cultural differences] I look to the clients to teach me.” In general, therapists felt that clients appreciated their mentioning racial/ethnic differences in session.

Therapist participants also reported that being conscious of ethnic/racial differences is important, even if they are not expressed. One white female therapist reported that "in the back of our minds, [we] are trying to be sensitive to anything that might come up that might be a cultural thing that we don't understand, or haven't been exposed to.” Therapists recognized ethnic/racial differences but didn’t always see them as a valid topic of discussion: "I don't think yet it has been apparent to be something that would lead us, or enhance what we're doing at this

point.” The therapists also seemed to believe that addressing ethnic/racial differences in treatment is ultimately determined by the client's needs: “I think it's a question for the clients, whether or not they think it is relevant. Not whether or not you think it is...."

Therapists, too, recognized the potential benefits of ethnically/racially matched client and therapist: 


\section{ETHNIC/RACIAL MATCHING}

...the fact that [female therapist] is African-American may have helped, just from the beginning, there may have been that connection for the clients, and I think the main thing is that [female therapist] and I joined well with them and listened to what they had to say and were respectful of them as people, and so they felt understood. That's the major thing, as long as they felt understood.

\section{DISCUSSION}

The findings of this study indicate that ethnic/racial matching within couples' treatment for domestic violence is multi-faceted. Thematic analysis supported this complexity by allowing room for rich detail. Participants connected the issue of ethnic/racial matching with a host of other issues including violence as a human problem, the benefit of shared understanding, and more. The findings also indicate that therapists' demonstrating cultural awareness and competence are significant factors with regard to the issue of ethnic/racial matching. Therapists and clients in this study reported that the cultural differences either between partners or between therapists and clients impacted treatment effectiveness more than the race of the therapist and/or client. The prominence of culture rather than race suggests that therapists' awareness of the cultural dynamic between partners as well as between client and therapist is important. Furthermore, clients in this study also described the qualities and skills of the therapist as impacting therapy more than ethnic/racial matching. Therapists' perceptions mirrored clients' experiences when they described an effort to be sensitive and culturally aware, while also noticing times they did not perceive ethnic/racial differences affecting therapy.

While this study expanded the issue of ethnic/racial matching to include other factors like the importance of therapist qualities, clients did report feeling ambivalent and unsure about the degree of influence of ethnic/racial matching. The salient theme of domestic violence as a 


\section{ETHNIC/RACIAL MATCHING}

“human” issue indicated that clients’ perceived domestic violence as transcending race. That is, couples reported that domestic violence was not a racial/ethnic issue but rather a "human" problem that occurred in every ethnic/racial group. Thus, while this appeared to be a robust theme, clients also reported feeling ambivalent about ethnic/racial matching in general. This ambivalence manifested not only in their language, but also in the tone of the interviews.

\section{STRENGTHS AND LIMITATIONS}

This study contributes to gaps in the literature regarding the importance of cultural competency in general and of ethnic/racial matching in particular in the area of domestic violence treatment. The use of a qualitative methodology further contributes to a more nuanced understanding of the complexity involved in the consideration of racial/ethnic matching in domestic violence treatment. The interviews allowed us to gain a better understanding of not only whether ethnic/racial matching was important for the clients and therapists involved in this treatment program, but more importantly, allowed us a better understanding of how matching or lack of matching was experienced and understood by those involved in the treatment program. However, there are some limitations to the use of secondary data analysis in this study. Although our data presented interesting findings, the interviews conducted during data gathering were not specifically targeted at the issue of ethnic/racial matching. Thus, it may be argued that the fullest amount of depth possible has not been obtained in our study. Additionally, the use of secondary data did not allow of any longitudinal follow-up with participants to see if their views of ethnic/racial matching in treatment have changed, nor were we able to include a measure of cultural identity to see how our participants’ levels of cultural identify related to their comments on the topic. Future studies may benefit from interviews that are specifically targeted at the issue of ethnic/racial matching. 


\section{ETHNIC/RACIAL MATCHING}

\section{IMPLICATIONS}

In addition to the research implications noted above, clinical implications may be derived from the findings. As mentioned, it is important for clinicians to be aware of the complexity regarding ethnic/racial matching. Just as variability within a specific ethnic/racial group exists, the impact from ethnic/racial matching may also vary. Making assumptions about what is best for a client based on ethnicity/race alone may limit the potential benefit a client gains from treatment. The influence of ethnicity/race will vary for an individual, often based on how identified that individual feels with a particular ethnic/racial group. Thus, we discourage clinicians from prescribing a set of practices based on a client’s ethnicity/race alone.

Instead, we recommend that clinicians engage in an open and affirming dialogue about ethnicity/race with their clients, regardless of whether the therapy dyad is ethnically/racially matched. For example, a client and therapist may "match" in regards to ethnicity/race, however, differences in how identified the therapist or client is with that particular ethnic/racial group may not lead to the assumed benefit of matching. Furthermore, assigning client's to therapists based on ethnic/racial matching alone limits other potentially beneficial characteristics that might “match” client and therapist (e.g. personality style, age, gender).

Conversely, just as it is important not to assume ethnic/racial matching will be helpful for clients, it is important not to assume that ethnic/racial matching will not be helpful for clients. We recommend that clinicians working with clients of a different ethnicity/race verbalize these differences in a safe and affirming manner. As was the case with our findings, many clients may indicate that ethnicity/race is not an issue related to treatment; however, it is important not to assume this for all clients. Thus, we recommend allowing clients to determine the degree of ethnic/racial issues to be addressed in treatment. 


\section{References}

Babcock, J. C., Green, C. E., \& Robie, C. (2004). Does batterers' treatment work? A metaanalytic review of domestic violence treatment. Clinical Psychology Review, 23, 10231053.

Braun, V., \& Clark, V., (2006) Using thematic analysis in psychology. Qualitative Research in Psychology, 3, 77-101.

Cabral, R. R., \& Smith, T.B. (2011) Racial/Ethnic matching of clients and therapists in mental health services: A meta-analytic review of preferences, perceptions, and outcomes. Journal of Counseling Psychology. Advance online publication.

Chang, D. F., \& Berk, A. (2009). Marking cross-racial therapy work: A phenomenological study of clients' experiences of cross-racial therapy. Journal of Counseling Psychology, 56(4), 521-536.

Cross, W.E. (1971) Negro-to-Black conversion experience: Toward a psychology of Black liberation. Black World, 20, 13-27.

DeShazer, S. (1988). Clues: Investigating Solutions in Brief Therapy. New York: W.W. Norton \& Company.

de Shazer, S., Dolan, Y., Korman, H., Trepper, T., McCollum, E., \& Berg, I. K. (2007). More than Miracles: The State of the Art of Solution-Focused Brief Therapy. Binghamton, NY: The Haworth Press. 


\section{ETHNIC/RACIAL MATCHING}

Farsimadan, F., Draghi-Lorenz, R., \& Ellis, J. (2007). Process and outcome of therapy in ethnically similar and dissimilar therapeutic dyads. Psychotherapy Research, 17(5), 567575.

Flicker, S. M., Waldron, H. B., Turner, C. W., Brody, J. L., \& Hops, H. (2008). Ethnic matching and treatment outcome with Hispanic and Anglo substance-abusing adolescents in family therapy. Journal of Family Psychology, 22(3), 439-447.

Gondolf, E.W. (2008). Program completion in specialized batterer counseling for AfricanAmerican men. Journal of Interpersonal Violence, 23(1), 94-116.

Gondolf, E.W., \& Williams, O.J. (2001). Culturally focused batterer counseling for African American men. Trauma, Violence \& Abuse,2(4), 283-295.

Hancock, T.U., \& Siu, K. (2009). A culturally sensitive intervention with domestically violent Latino immigrant men. Journal of Family Violence, 24, 123 -132.

Helms, J.E. \& Carter, R.T. (1991) Relationships of white and black racial identity attitudes and demographics similarity to counselor preferences. Journal of Counseling Psychology, 38, 446-457.

Hill, C.E. ed. (2012). Consensual qualitative research. American Psychological Association: Washington, D.C.

Knox, S., Burkard, A. W., Johnson, A. J., Suzuki, L. A., Ponterotto, J. G. (2003). African American and European American therapists’ experiences of addressing race in crossracial psychotherapy dyads. Journal of Counseling Psychology, 50 (4), 466-481.

McCollum, E. E., \& Stith, S. M. (2008). Couples treatment for interpersonal violence: A review of outcome research literature and current clinical practices. Violence and Victims, 23(2), 187-201. 


\section{ETHNIC/RACIAL MATCHING}

Murphy, M. J., Faulkner, R. A., \& Behrens, C. (2004). The effect of therapist-client racial similarity on client satisfaction and therapist evaluation of treatment. Contemporary Family Therapy, 26(3), 279-292.

Ponterotto, J., Casa, J., Suzuki, L. \& Alexander, C. (1995). Handbook of Multicultural Counseling. Thousand Oaks, CA: Sage.

Parham, T.A. \& Helms, J.E. (1981) The influence of black students' racial identity attitudes on preference for counselor’s race. The Journal of Counseling Psychology, 28, 250-257.

Patton, M. Q. (2002). Qualitative research and evaluation methods. Thousand Oaks, CA: Sage.

Rosenheck, R., Fontana, A., \& Cottrol, C. (1995). Effect of clinician-veteran racial pairing in the treatment of posttraumatic stress disorder. The American Journal of Psychiatry, 152(4), $555-563$.

Sabnani, H., Ponterotto, J.G., \& Borodovsky, L.G. (1991) White racial identity development and cross-cultural counselor training: A stage model. The Counseling Psychologist, 19, 76102.

Shin, S., Chow, C., Camacho-Gonsalves, T., Levy, R. J., Allen, E. I., \& Leff, S. H. (2005). A meta-analytic review of racial-ethnic matching for African American and Caucasian American clients and clinicians. Journal of Counseling Psychology, 52(1), 45-56.

Sterling, R. C., Gottheil, E., Weinstein, S. P., \& Serota, R. (2001). The effect of therapist/patient race- and sex-matching in individual treatment. Addiction, 96(7), 1015-1022.

Stith, S. M., Rosen, K. H., McCollum, E. E., \& Thomsen, C. J. (2004). Treating intimate partner violence within intact couple relationships: Outcomes of multi-couple versus individual couple therapy. Journal of Marital and Family Therapy, 30, 305-318. 
ETHNIC/RACIAL MATCHING

Stith, S.M., McCollum, E.E., Amanor-Boadu, Y. \& Smith, D. (In press) Systemic Treatments for Domestic Violence. Journal of Marital and Family Therapy.

Stith, S.M., McCollum, E. E., \& Rosen, K. H. (2011). Couples Treatment for Domestic Violence: Finding Safe Solutions. American Psychological Association, Washington, D.C.

Sue, S., Fujino, D. C., Hu, L., and Takeuchi, D. T. (1991). Community mental health services for ethnic minority groups: A test of the cultural responsiveness hypothesis. Journal of Consulting and Clinical Psychology, 59(4), 533-540.

Taft, C. T., Murphy, C.M., Elliot, J. D., \& Keaser, M. C. (2001). Race and demographic factors in treatment attendance for domestically violent men. Journal of Family Violence, 16(4), 385-400.

U.S. Surgeon General. (2001). Mental health: Culture, race, and ethnicity. A supplement to Mental Health: A Report of the Surgeon General. Rockville, MD: U.S. Department of Health and Human Services.

Vincent, G. K., \& Velkoff, V. A. (2010). The next four decades, the older population in the United States: 2010 to 2050. Current Population Reports, P25-1138, Washington, DC: U.S. Census Bureau.

Wintersteen, M. B., Mensinger, J. L., \& Diamond, G. S. (2005). Do gender and racial differences between patient and therapist affect therapeutic alliance and treatment retention in adolescents? Professional Psychology: Research and Practice, 36(4), 400-408.

Table 1

Background information on each couple and their respective therapists

\begin{tabular}{lllll}
\hline Couple Clients' Race & Age Completed & Therapists' Age
\end{tabular}




\begin{tabular}{|c|c|c|c|c|c|}
\hline & & & Sessions & race & \\
\hline \multirow[t]{2}{*}{1} & $\begin{array}{l}\text { Black male born in } \\
\text { South American }\end{array}$ & 35 & 12 & White female & 34 \\
\hline & Black female & 29 & 12 & White female & 33 \\
\hline \multirow[t]{2}{*}{2} & Black male & 41 & 12 & White male & 28 \\
\hline & Black female & 35 & 12 & Black female & 32 \\
\hline \multirow[t]{2}{*}{3} & Black male & 54 & 12 & Black female & 33 \\
\hline & Black female & 46 & 12 & White male & 28 \\
\hline \multirow[t]{2}{*}{4} & $\begin{array}{l}\text { White male from } \\
\text { Europe }\end{array}$ & 37 & 12 & White male & 28 \\
\hline & $\begin{array}{l}\text { Asian female born } \\
\text { outside the U.S.A }\end{array}$ & 40 & 12 & White female & 26 \\
\hline \multirow[t]{2}{*}{5} & $\begin{array}{l}\text { Black/Hispanic/Latin } \\
\text { male }\end{array}$ & 47 & 12 & White male & 28 \\
\hline & White female & 47 & 12 & White female & 34 \\
\hline \multirow[t]{2}{*}{6} & Black male & 22 & 7 & $\begin{array}{l}\text { White male } \\
\text { from South } \\
\text { American }\end{array}$ & 26 \\
\hline & Black female & 22 & 7 & White female & 32 \\
\hline \multirow[t]{2}{*}{7} & $\begin{array}{l}\text { Asian male born outside } \\
\text { the U.S.A }\end{array}$ & 26 & 4 & White male & 28 \\
\hline & White female & 19 & 4 & Black female & 32 \\
\hline
\end{tabular}

